\title{
GEMS: GIS and geo-statistics integrated in Brownfield remediation and redevelopment, applied in the Vilvoorde region
}

\author{
P. Schrooten \& A. Van Alphen \\ Soresma NV, Antwerp, Belgium
}

\begin{abstract}
Belgium was one of the first European countries to become industrialised. The initial industrialisation has caused numerous soil and groundwater contaminations. Almost 70 years later, these contaminations became a major issue of concern for the redevelopment of former industrial areas. Real-estate developers are familiar with the costs for demolishing and redeveloping industrial areas, but less with the cost due to soil contamination. Two types of costs associated with the contamination can be identified: (1) the cost for the remediation (removing risks) and (2) the cost for treatment of the less contaminated soil during construction works (redevelopment). Due to these important cost factors, the need to assess them more reliably becomes more important.
\end{abstract}

To address this issue the GEMS (Geographic Environmental/Economical Management System) tool was developed. This GIS based programme allows the designation of different types of land use to different areas (e.g. housing, industry, roads, green areas...) of the redevelopment area. For each drawn land use specific parameters need to be added (depth of underground constructions, percentage of surface area excavated for underground lines...). The model then determines which volume of soil will need to be remediated based on the selected land use and parameters. This is automatically done for a risk-based and reference value remediation target. It also determines the remaining volume of soil that needs to be excavated based on the planned infrastructure and that which needs further treatment before it can be reused. For these volumes of soil a cost is calculated based upon the type of contamination and the contamination levels.

The basis of the model is a geo-statistical 3D contamination map for different types of contaminant groups (BTEX, TPH, PAH, heavy metals, cyanides...). These maps are calculated from site measurements. A first working example of the GEMS tool was developed for the Watersite Brownfield project (Novovil) in the city of Vilvoorde. In the past a large portion of Vilvoorde city was used for heavy industry. It also incorporated some major traffic lines, some scattered housing and a railway. The GEMS tool allowed the Watersite Brownfield developers to model different urban planning scenarios in order to determine the most ideal scenario for the future redevelopment.

Keywords: regional redevelopment, GIS, geo-statistics, soil contamination. 


\section{Introduction}

In the $19^{\text {th }}$ century the industrial revolution created new kinds of work. Large manufactories were created along important waterways or close to city centres. In the beginning the industrial processes were very crude, and wastes were mostly dumped on-site. At the beginning of the $20^{\text {th }}$ century the chemical industry became one of Belgium's most important industrial activities. Belgium was one of the five leading industrialised countries in the world. An important area at that time was situated north of Brussels in the Vilvoorde area (Figure 1), along the Brussels-Mechelen canal. Different types of industrial activities were present: foundries, coking plants, refineries, solvent treatment, paint production, basic chemical industrial activities, etc (Figure 1). From the 1970s onward the area became more and more derelict. At that time the industrial facilities had surrounded the housing areas and major traffic ways were constructed (railways and motorway). In the following decades more and more factories were closed.

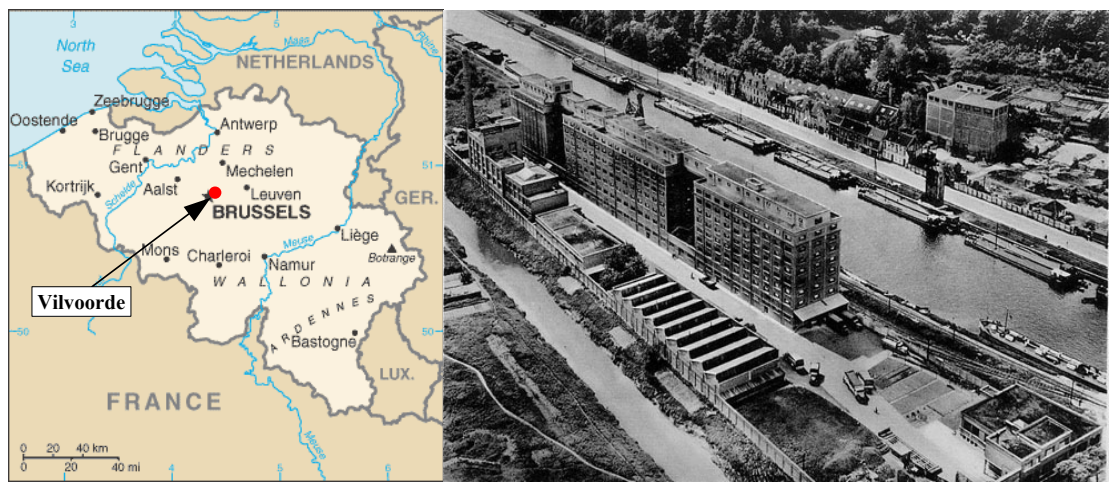

Figure 1: Vilvoorde location and industry in around 1930.

At the end of the 1990s the local authorities decided to start redevelopment of the area, to allow for new industrial activities and improve housing and mobility. The Brownfield redevelopment project "Watersite" was born. Ten years later only a few areas of the Watersite project were under redevelopment. One of the major obstacles in the redevelopment process was the unknown cost related to the remediation of the soil and groundwater contamination caused by the former industrial activities. Almost 20 years of soil and groundwater investigation in this area had shown numerous contaminant sources and types impacting several hundred thousands of $\mathrm{m}^{2}$. Several areas are heavily contaminated and need urgent remediation or safety measures. Other areas where industrial reuse was possible, did not allow for residential redevelopment without remediation.

The Flemish soil decree regulates all issues concerning contaminated soil and groundwater. Strict remediation targets depending on the land use (residential, industrial, agriculture, etc) are defined in this legislation. In some cases, after BATNEEC evaluation, other, more risk based remedial targets are allowed. Another part of this law deals with soil that is only slightly contaminated, but when excavated, cannot be reused as soil due to the contamination present. This 
type of soil brings along extra costs for the redeveloper, as he needs to clean this soil before reuse. Soil that is not excavated can be left in place as long as it does not pose a risk for humans or the environment.

Confronted with the unknown costs related to the soil and groundwater contamination and the Flemish soil legislation, the Vilvoorde Brownfield manager (Novovil) commissioned Soresma to develop a working tool to determine the costs based on the remediation of the contaminations present for different redevelopment plans taking into account the soil legislation. The developed tool, called "GEMS" (Geographic Environmental/Economical Management System), is an application where 3D geo-statistics and GIS are combined to create a dynamic and flexible evaluation tool in Brownfield redevelopment.

\section{Geo-statistics: the basis of GEMS}

Geo-statistics were developed in exploration geology to determine ore volumes based on point measurements. Essentially, geo-statistics combine the numerical value of the measurement with its spatial location to determine the values of other points in the project area. Detailed information on the use of geo-statistics in environmental applications can be found in Goovaerts [1] and Sanchez-Villa [2]. The GEMS tool needed a 3D representation of the different contaminations to determine the soil volumes that need remediation or the quality of the soil that will be excavated for construction works. The principle of determining ore volumes by geo-statistics is similar to that of determining soil contamination volumes. Data is collected based on chemical analyses from point samples [3-6].

Therefore the first step in the geo-statistical evaluation was to collect site data measurements. This data was obtained from the Flemish waste agency (OVAM). This authority evaluates and collects all soil and groundwater investigations undertaken in the Flemish region of Belgium. This data is collected in a GIS linked database. The soil and groundwater analyses in this database are defined by unique XYZ-coordinates. A polygon of 240 ha overlapping more than the Watersite Brownfield area was defined. The OVAM then provided all soil and groundwater analyses in their database located in this polygon. In total 2230 sample points were obtained. The measurements at these sample points comprised analyses for heavy metals, $\mathrm{PAH}, \mathrm{BTEX}, \mathrm{TPH}$, cyanides, $\mathrm{VOCl}$ and EOX.

The next step in the geo-statistical evaluation is the clean-up and statistical evaluation of the obtained data. Double analyses, sample points without measurements and monitoring data were removed from the dataset. These fake analyses can result in "phantom" effects in the final 3D maps. Monitoring results or double analyses can result in over or underestimations of the calculated concentrations.

To minimise computer time and limit model size, it was decided not to work with all analytical parameters (contaminant compounds). Therefore guide parameters were selected for each parameter group (PAH, heavy metals...). Table 1 presents the different guide parameters for each parameter group. 
Table 1: $\quad$ Guide parameters.

\begin{tabular}{|c|c|c|}
\hline \multirow[t]{2}{*}{ Parameter group } & \multicolumn{2}{|c|}{ Guide parameter } \\
\hline & Soil & Groundwater \\
\hline Heavy metals & $\begin{array}{l}\text { cadmium } \\
\text { chrome } \\
\text { lead } \\
\text { zinc }\end{array}$ & $\begin{array}{c}\text { arsenic } \\
\text { chrome } \\
\text { mercury } \\
\text { lead }\end{array}$ \\
\hline PAH & $\begin{array}{c}\text { benzo(a)pyrene } \\
\text { naftalene }\end{array}$ & $\begin{array}{c}\text { naftalene } \\
\text { fluoranthene } \\
\text { benzo(a)pyrene }\end{array}$ \\
\hline BTEX & $\begin{array}{l}\text { benzene } \\
\text { toluene }\end{array}$ & $\begin{array}{l}\text { benzene } \\
\text { toluene } \\
\text { xylene }\end{array}$ \\
\hline TPH & TPH (total GCMS/IR) & TPH (total GCMS/IR) \\
\hline $\mathrm{VOCl}$ & $\begin{array}{c}\text { PCE } \\
\text { TCE } \\
\text { DCE } \\
\text { VC }\end{array}$ & $\begin{array}{c}\text { PCE } \\
\text { TCE } \\
\text { DCE } \\
\text { VC } \\
\end{array}$ \\
\hline Cyanides & $\begin{array}{l}\text { total cyanides } \\
\text { free cyanides }\end{array}$ & Total cyanides \\
\hline
\end{tabular}

Table 2: $\quad$ Flemish remediation values.

\begin{tabular}{|l|c|c|}
\hline \multirow{2}{*}{ Guide parameters } & \multicolumn{2}{|c|}{ Flemish remediation values } \\
\cline { 2 - 3 } & $\begin{array}{c}\text { Soil }(\mathbf{m g} / \mathbf{k g} \text { d.m. } \\
\text { Housing (type III) }\end{array}$ & Groundwater $(\boldsymbol{\mu g} / \mathbf{l})$ \\
\hline arsenic & & 20 \\
cadmium & 4 & 50 \\
chrome & 256 & 20 \\
lead & 614 & 1 \\
mercury & & \\
zinc & 1,44 & 0,7 \\
\hline benzo(a)pyrene & 4 & 60 \\
naftalene & & \\
fluoranthene & 0,5 & 10 \\
\hline benzene & & 700 \\
toluene & & 500 \\
xylene & 500 & 500 \\
\hline TPH & 0,7 & 40 \\
\hline PCE & 0,7 & 70 \\
TCE & 0,4 & 50 \\
DCE & 0,01 & 5 \\
VC & 12 & 70 \\
\hline total cyanides & 5 & \\
free cyanides & & \\
\hline
\end{tabular}

The available values of the sample points represent absolute soil or groundwater concentrations for a certain parameter. Absolute values cannot be used to make comparisons between different types of parameters representing different toxicological, physical or chemical properties or to compare the amount of contamination between different locations. To resolve this problem all concentrations were divided by the remediation values (Table 2) as defined in the Flemish legislation. These values are based on toxicological studies, so the resulting value of this division is a factor that gives an indication of the human toxicological impact of the contamination. These factors allow comparison between different parameters and give an overall indication of the impact of the different contaminant parameters at a certain location by adding the factors. 
As presented above, different remediation values were developed for five different land use types. This means that for each land use type (housing, nature, agriculture, industry and recreation) different contamination factors need to be calculated. The impact of the contamination is therefore not only dependent on the physico-chemical and toxicological properties of the parameter but also on the land use of the contaminated area.

Taking into account the conceptual redevelopment plans for the Vilvoorde project area only three land-use types were selected: housing, recreation and industry. For each of these three types a geo-statistical evaluation was performed.

The calculated contamination factors were used in the geo-statistical evaluation to create $3 \mathrm{D}$ contamination maps. First a 3D grid was defined. The 3D grid represents the soil; each block of the grid is a soil volume for which a contamination factor is calculated. This grid comprises blocks with a surface of 5 x $5 \mathrm{~m}$ and a thickness of $0,5 \mathrm{~m}$ (a volume of $12,5 \mathrm{~m}^{3}$ ). The geo-statistical evaluation based on the distribution of the available data calculates the "most likely" contamination factor.

Indicator Kriging methodology was used to calculate the contamination factors for the soil blocks. This methodology takes into account the distribution of dataset values in indicator classes, defined by threshold values, resulting in more smoothed volumes. The model parameters for the different steps (threshold indicator evaluation, semi-variogram analyses, post-processing) in Indicator Kriging were determined for each individual guide parameter. The calculations were performed with Vesper 1.6 and WinGslib 1.4 geo-statistical software. The geo-statistical evaluation resulted in 3D contamination maps for each of the guide parameters. Figure 2 shows a detail overview of the contamination of the Vilvoorde project area for $\mathrm{PAH}$ (the colours indicate the amount of contamination: darker areas: no contamination above the Flemish remediation values (FRV), lighter shaded areas: gradually exceeding the FRVs).

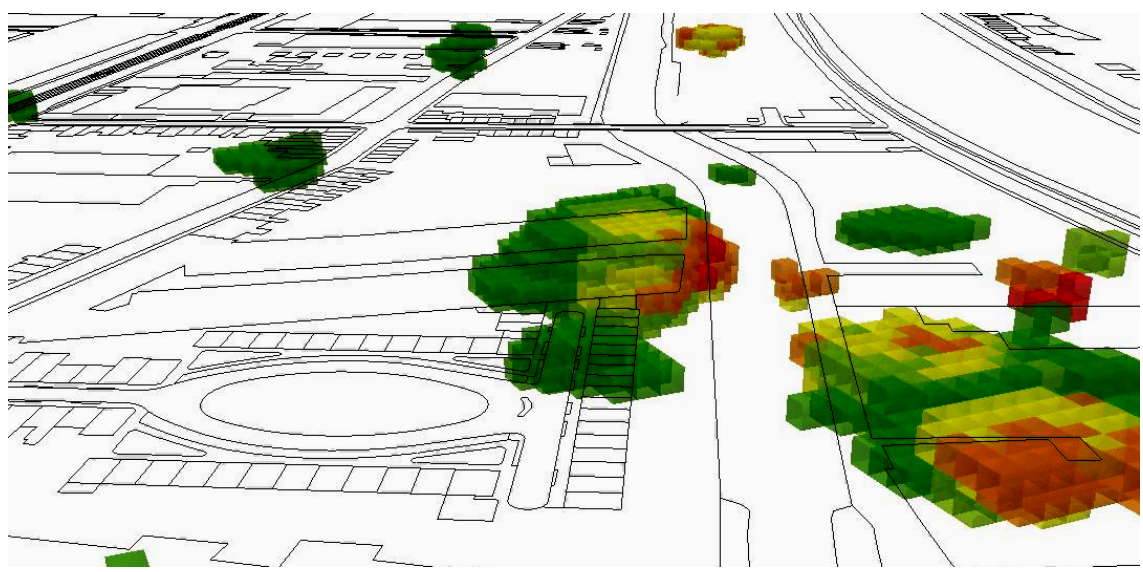

Figure 2: Detailed overview of the soil contaminations for PAH. 
The soil contamination maps were only calculated to a depth of 4,5 m below ground level. The available data for the deeper soil was not sufficient to calculate reliable contamination volumes.

A similar evaluation was undertaken for the groundwater contamination. The Flemish remediation values used to calculate the contamination factors for groundwater are not land use dependent. So only one 3D geo-statistic evaluation was necessary. The same $3 \mathrm{D}$ grid size was applied for groundwater. The contamination factors were calculated for a depth interval from $2 \mathrm{~m}$ to $10 \mathrm{~m}$ below ground level. The overall groundwater table at the project location is present at approximately 2 to $3 \mathrm{~m}$ below ground level.

\section{Cost module: theoretic model}

The next step in the development is the integration of a cost assessment based on the soil contamination and the planned redevelopment areas. The cost we want to determine is dependent on (1) if or not the soil needs to be excavated due to contamination and/or construction works, (2) if or not this soil is contaminated and (3) how much it is contaminated. Non-contaminated soil will have normal excavation and transport costs. Slightly contaminated soil may have a higher cost due to the necessary treatment. Heavily contaminated soil may need extra measurements and treatment that bring along even more costs.

In order to determine if a soil at a certain plot needs to be excavated for a remediation, the planned land use needs to be determined. This is done by designating the plot with one of the three land use types (housing, industry or recreation). Then all 3D contamination maps for this land use are consulted to determine if soil blocks with contamination factors equal to or above 1 are present in the designated area. If this is the case than the soil contamination poses a risk to humans and needs to be remediated. For the blocks where the contamination factor is smaller than 1 excavation might be necessary due to planned construction works. In order to determine this construction input parameters for underground facilities (basement, foundations, service lines, sewage...) are added to the attributes of the evaluated plot. Based on these parameters a soil volume can be calculated. The quality of the soil (i.e. individual values of the contamination factors of the soil blocks) will determine if (or not) soil is contaminated and how much it is contaminated. This is in relation to the legal remediation values, the soil clean-up technique and cost. Figure 3 gives a schematic overview of the above mentioned evaluation.

By implementing the above described evaluation the exact volumes of excavated soil for remediation and for construction works can be calculated by adding up the soil blocks from the 3D grid. For each of these individual blocks the CFs and the contamination parameters will determine what treatment techniques can be used. To limit the potential options of soil treatment only the following technologies were considered: biological treatment, physico-chemical treatment (soil washing), thermal treatment and landfill. This allowed putting concrete unit costs per volume of soil into the evaluation model. A cost for the excavation and transport of clean soil was also added. 


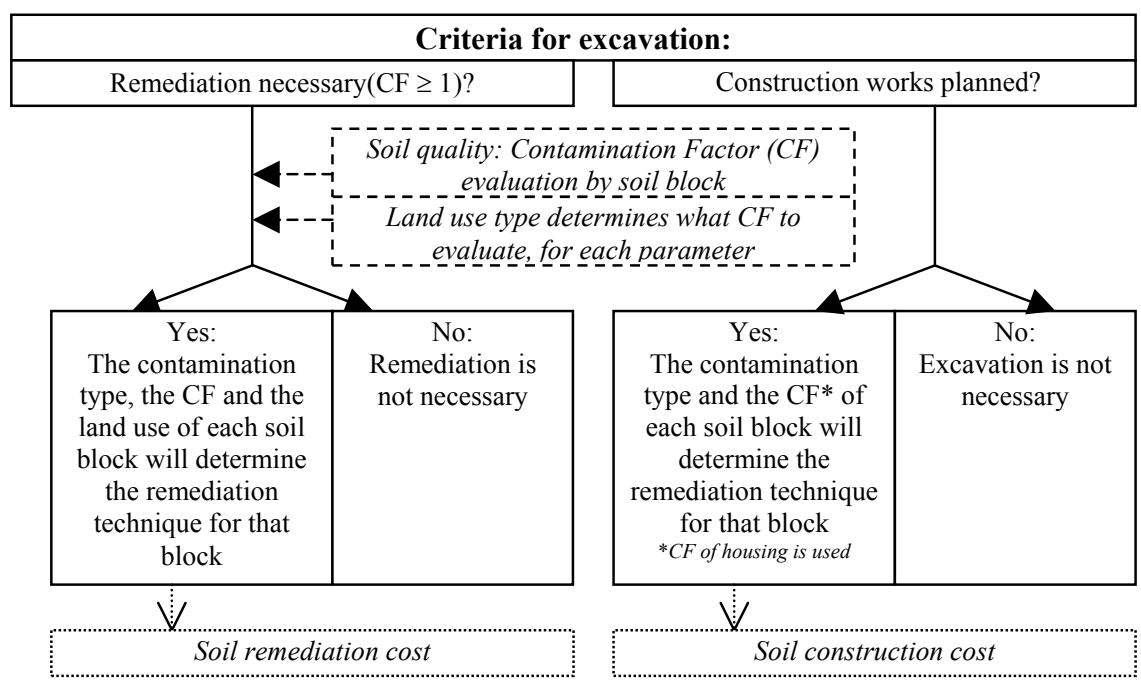

Figure 3: $\quad$ Evaluation diagram for excavation criteria.

\section{GIS: integrating 3D maps, the cost module and spatial planning}

A GIS application was developed in ArcView 9.2 to integrate the 3D contamination maps with the spatial planning scenarios and the cost module:

- The 3D contamination maps were transformed in 2D+ layers. This means that each $0,5 \mathrm{~m}$ thick soil layer became a flat data layer in the GIS application. Thickness was no longer a dimension but is represented by an individual attribute layer;

- A cadastral map is used as a background for the spatial planning layer. The cadastral map was selected to allow the user to draw development scenarios based on the current spatial planning layout on a cadastral parcel scale. The spatial planning layer is the only editable layer in the model. This is necessary so different planning scenarios can be evaluated. Spatial planning scenarios are entered in the model by drawing shapes in this layer and adding dimension and land use attributes to the shapes;

- The cost module is integrated as linear logical functions that use parameters from the spatial planning layer and the contamination layers. Cost parameters for different types of remediation or soil treatment techniques are also a part of the cost module. These parameters can be changed in the function of the site-specific criteria of the evaluated Brownfield project.

Figure 4 represents the schematic build-up of the integrated GIS application.

Several GIS Brownfield GIS applications have already been developed. Most of them focus on the identification of potential Brownfield sites or the evaluation of land-use and stakeholders [7, 8]. A flexible GIS application to evaluate the soil pollution and costs as presented above is not available. 


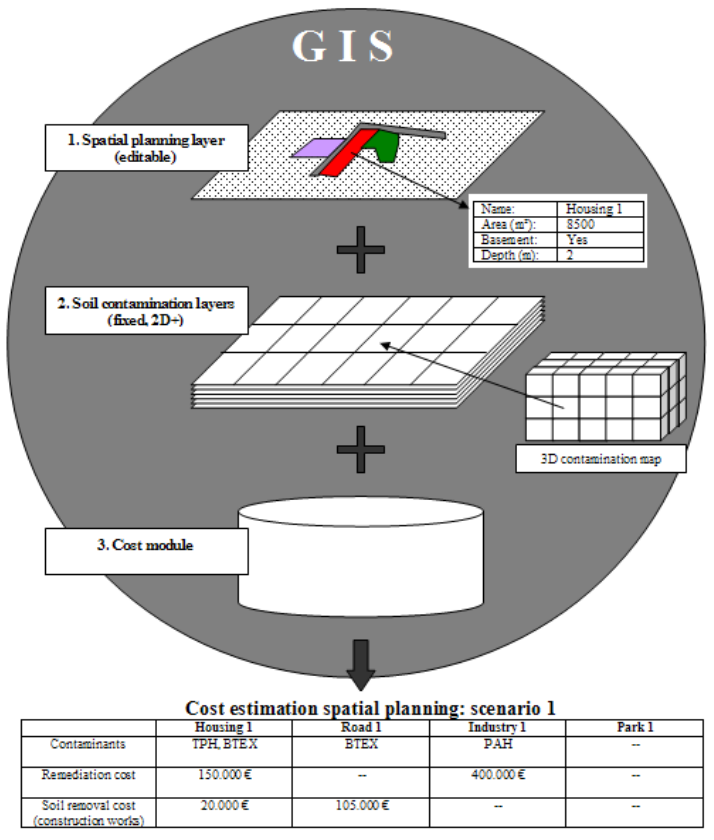

Figure 4: Integrated GIS.

(a)

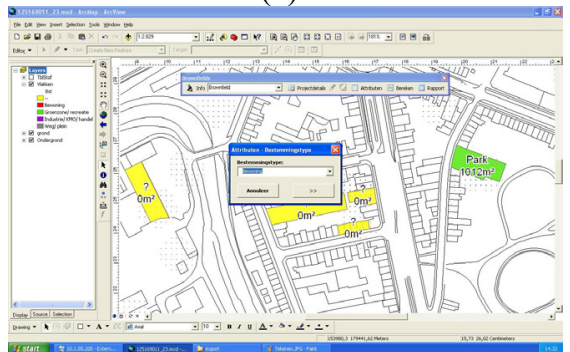

(c)

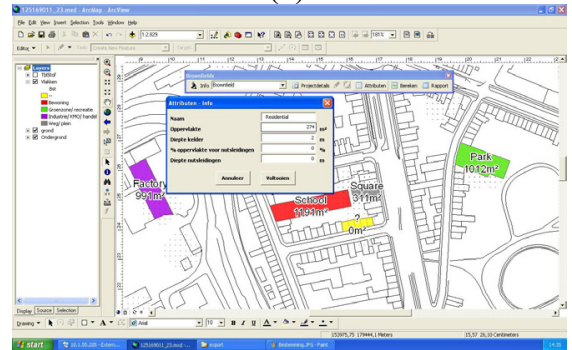

(b)

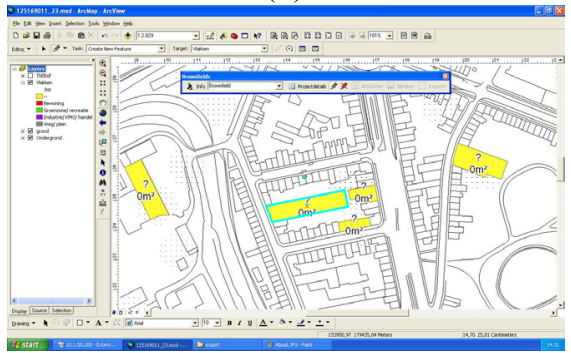

(d)

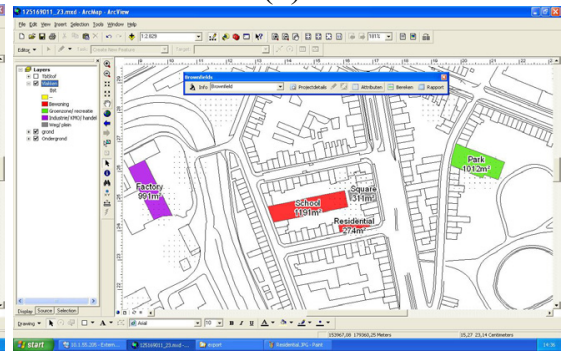

Figure 5: Screenshots of GEMS. 


\section{Case: Vilvoorde}

The first fully working GEMS tool was developed for the Watersite Brownfield project in Vilvoorde city. It comprised a total area of 185 ha with a total of $94.500 \mathrm{~m}^{3}$ of contaminated soil down to $4,5 \mathrm{~m}$ below ground level. Figure 5 shows several screenshots of the GIS application ((a) drawing zones, (b) designating land use, (c) adding attributes and (d) reporting).

\section{Conclusion}

The integration of 3D geo-statistics and GIS in the development of the GEMS Brownfield redevelopment tool resulted in a flexible instrument to minimise the remediation costs in the function of spatial planning. The developed methodology will aid in a better understanding of the influence of spatial planning on remediation costs. Real-estate calculation modules are under development and will be added to the GEMS tool to allow investment and profit evaluation.

\section{References}

[1] Goovaerts, P. Geostastics for Natural Resources; Oxford University Press, pp. 483, 1997

[2] Sanchez-Vila, X., Carrera, J. and Gómez-Hernández, J., geoENV IV Geostatistics for Environmental Applications, pp. 560, 2004

[3] A. Facchinelli, E. Sacchi, and L. Mallen, Multivariate statistical and GISbased approach to identify heavy metal sources in soils, Environmental Pollution Volume 114, issue 3, pp. 313-324, 2001

[4] Stein, A., Modelling spatial variability of soil pollution variables with geostatistics for environmental purposes, Proc. 1st Eur. Conf. Integrated research for soil and sediment protection and remediation (EUROSOL), Maastricht 1992. Integrated soil and sediment research: a basis for proper protection, H.J.P. Eijsacker, T. Hamers (eds.). Wageningen, pp. 431-434, 1993

[5] Fabbri, P. and Trevisani, S., A Geostatistical Simulation Approach to a Pollution Case in Northeastern Italy, Mathematical Geology, Springer Netherlands, pp. 569-586, 2005

[6] Malherbe, A., Designing a contaminated soil sampling strategy for human health risk assessment, Accreditation and Quality Assurance: Journal for Quality, Comparability and Reliability in Chemical Measurement, Springer Germany, pp. 189-194, 2004

[7] Boott, R., Haklay, M., Heppell, K. and Morley, J., The Use of GIS in Brownfield Redevelopment in Innovations in GIS 8: Spatial Information and the Environment, Halls, P. (Ed.), Taylor and Francis, London. pp. 241-258, 2001 
64 Brownfields IV

[8] C. Atturo, C. Cianfrone, V. Ferrara, L. Fiumi, G. Fontinovo \& C. M. Ottavi, Remote sensing detection techniques for brownfield identification and monitoring by GIS tools, Brownfield Sites III, WIT Press, pp. 241-250, 2006 